\title{
Evaluación de los efectos del glifosato y otros plaguicidas en la salud humana en zonas objeto del programa de erradicación de cultivos ilícitos
}

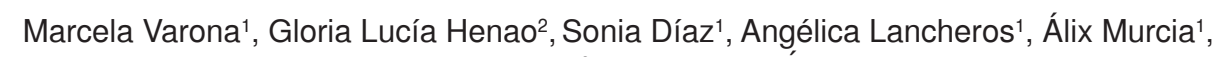 \\ Nelcy Rodríguez ${ }^{3}$, Víctor Hugo Álvarez ${ }^{4}$ \\ 1 Grupo de Salud Ambiental, Instituto Nacional de Salud, Bogotá, D.C., Colombia \\ 2 Grupo de Factores de Riesgo Ambiental, Instituto Nacional de Salud, Bogotá, D.C., Colombia \\ 3 Grupo de Métodos en Bioestadística, Universidad Nacional de Colombia, Bogotá, D.C., Colombia \\ ${ }^{4}$ Grupo de Vigilancia en Salud Pública, Ministerio de la Protección Social, Bogotá, D.C., Colombia
}

Introducción. El Programa de Erradicación de Cultivos Ilícitos con Glifosato se ejecuta dando cumplimiento a lo establecido en el Plan de Manejo Ambiental.

Objetivo. Explorar los posibles efectos del glifosato y otros plaguicidas sobre la salud humana como resultado de las aspersiones aéreas.

Materiales y métodos. Se realizó un estudio descriptivo en 112 individuos procedentes de las áreas asperjadas de los departamentos de Huila, Tolima, Putumayo, Guaviare, Santander, Antioquia, Magdalena y La Guajira, durante 2005 y 2006. Se aplicó una encuesta y se recolectaron muestras de orina para la determinación de glifosato, y de sangre, para la determinación de acetilcolinesterasa y organoclorados. Se llevó a cabo un análisis simple y se exploraron las posibles asociaciones.

Resultados. El 50,0\% (56 individuos) de la población manifestó el uso de plaguicidas en su trabajo. El tiempo que llevaban utilizando los plaguicidas fue de 84,8 meses y refirieron aplicar plaguicidas 5,6 horas al día. El predominio de los plaguicidas usados fue extremadamente tóxico. De $39,6 \%$ de los individuos a quienes se les cuantificó glifosato, 64,3\% reportaron su uso en actividades agrícolas. Se encontró una relación estadísticamente significativa entre el uso de glifosato terrestre (manual) y los niveles de este herbicida en orina $(O R=2,54$; IC95\% 1,086,08).

Conclusión. No hubo hallazgos concluyentes entre la exposición a glifosato empleado en la erradicación de cultivos ilícitos y los efectos en la salud, debido a que se halló exposición ocupacional concomitante por la misma sustancia y por otras de mayor toxicidad que el glifosato.

Palabras clave: plaguicidas, herbicidas, exposición a plaguicidas, exposición a riesgos ambientales, riesgo, toxicidad.

Effects of aerial applications of the herbicide,glyphosate and insecticides on human health

Introduction. The herbicide glyphosate is administered aerially by the Program to Eradicate Illicit Crops Program and is undertaken in rigorous compliance with the Environmental Management Plan.

Objective. The effects of the glyphosate herbicide and other aerially applied insecticides were measured to determine possible impact on human health.

Materials and methods. In 2006-2006, a survey was taken of 112 individuals living in herbicidetreated areas of the Colombian provinces of Huila, Tolima, Putumayo, Guaviare, Santander, Antioquia, Magdalena and La Guajira. Samples of blood were examined for presence of acetylcholinesterase and organochlorine insecticides; urine was analyzed for glyphosate and its metabolites.

Results. Fifty percent (50\%) of the individuals sampled acknowledged the use of control chemicals as part of their work. The mean exposure time to the chemicals was 84.4 months, with a mean 
daily exposure of 5.6 hours. The most commonly used pesticides were of category l--extremely hazardous. In individuals sampled for glyphosate (39.6\% of the total), $64.3 \%$ indicated the use of this herbicide at ground level in agricultural work. A statistically significative relationship was found between the use of glyphosate at ground level, and the concentration levels of glyphosate in the urine samples (odds ratio=2.54, 95\% Cl: 1.08 to 6.8 ).

Conclusion. These data did not show a relationship between the aerial sprayings of glyphosate for illicit crops eradication and an impact on human health, nor with occupational exposure to this and other chemicals (insecticides) with a high levels of toxicity.

Key words: pesticides, herbicide, pesticide exposure, environmental exposure, toxicity

En enero de 1992, el Consejo Nacional de Estupefacientes autorizó la aspersión aérea controlada de cultivos ilícitos, mediante el empleo del agente químico glifosato, después de haber evaluado diferentes herbicidas $y$, en noviembre de 2001, mediante la Resolución 1065, en ese entonces el Ministerio del Medio Ambiente, impuso el Plan de Manejo Ambiental a la Dirección Nacional de Estupefacientes, ejecutándose a partir de la Resolución 1054 del 2003 con el fin de dar seguimiento a todas la actividades objeto del Programa de Erradicación de Cultivos llícitos con Glifosato .

El inicio de las aspersiones trajo consigo innumerables quejas, las cuales se referían a afectaciones de los cultivos lícitos, de los animales, del ambiente y de la salud humana. Aunque la evaluación de riesgo del herbicida y su clasificación toxicológica (1) mostraba el bajo riesgo de su uso, el Ministerio de la Protección Social, como autoridad competente en el tema, propuso un estudio el cual se llevó a cabo en forma conjunta con el Instituto Nacional de Salud, para recolectar evidencias epidemiológicas que permitieran una mejor comprensión sobre los efectos agudos que se podrían estar ocasionando como consecuencia de la aplicación de la mezcla utilizada.

En relación con los plaguicidas empleados en el país, la Dirección Nacional de Estupefacientes y la Sección de Asuntos Narcóticos de la Embajada de los Estados Unidos publicaron, en 1999, un

Correspondencia:

Marcela Varona, Grupo de Salud Ambiental, Instituto Nacional de Salud, calle 26 No. 51-20, Bogotá, D.C., Colombia.

Telefax: (571) 2207700 , extensión 447

mvarona@ins.gov.co

Recibido: 26/09/08; aceptado:13/04/09 informe en el que se reportó que $98,7 \%$ de los cultivadores utilizaban insecticidas y fungicidas para controlar las plagas y enfermedades; $92,5 \%$ utilizaba fertilizantes químicos y $95,5 \%$ controlaba la competencia de otras plantas con herbicidas (Uribe S. Proyecto sobre rendimientos de las plantaciones de coca en Colombia, Informe de progreso № 5. Bogotá, octubre 25 de 1999). Por otro lado, la investigación del Instituto Amazónico de Investigaciones Científicas (SINCHI) muestra que los productores, al contrario de lo que acostumbran a hacer con su producción de pan coger, se esmeran por realizar labores agrícolas como desyerbar en sus cultivos ilícitos, al igual que acostumbran a controlar químicamente los insectos y plagas (2).

Otro reflejo del gran uso de plaguicidas es el reporte de intoxicaciones a través del Sistema de Vigilancia en Salud Pública Nacional (SIVIGILA), en el que se reportaron, para el 2006, un total de 8.777 intoxicaciones por sustancias químicas, de las cuales, $5.219(59,5 \%)$ correspondieron a intoxicaciones por plaguicidas y, para el 2007, se presentaron 12.848 intoxicaciones por sustancias químicas, $47,8 \%(6.141)$ de las cuales fueron por plaguicidas (3).

En relación con la aplicación operativa de la estrategia de aspersión aérea, ésta es ejecutada por la Dirección Antinarcóticos de la Policía Nacional.

En ese sentido, el Programa de Erradicación de Cultivos llícitos con Glifosato se ejecuta según lo establecido en el Plan de Manejo Ambiental (4, Sección Asuntos Narcóticos, Dirección de Antinarcóticos, Policía Nacional. Acercamiento a la actividad agronómica y la problemática ambiental de los cultivos de coca en Colombia. Documento técnico, 2005) y en el Decreto 1843 
de 1991 del Ministerio de Salud, que reglamenta el uso y manejo de plaguicidas en el territorio nacional (5). La verificación del cumplimiento del Plan de Manejo Ambiental la realiza el Ministerio del Medio Ambiente y Vivienda Territorial, mediante visitas de seguimiento a las diferentes áreas donde se adelantan las labores de aspersión (6)

El herbicida empleado para la erradicación de los cultivos ilícitos es el patentado por la casa

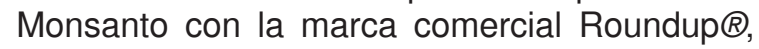
el cual está compuesto por $480 \mathrm{~g} / \mathrm{L}$ de la sal isopropilamina de $\mathrm{N}$-fosfonometilglicina. El glifosato es uno de los plaguicidas más ampliamente utilizados en todo el mundo; su uso incluye manejo agrícola, industrial, de jardinería ornamental y de malezas en las residencias, la formulación se encuentra registrada en más de cien países y es usado en 60 cultivos agrícolas, aproximadamente (4).

En el país, el glifosato es uno de los herbicidas más utilizados. Se emplea para madurar la caña de azúcar en el Valle del Cauca hace más de 30 años y, como herbicida, en cultivos de café, banano, arroz, cacao, palma africana y cítricos. Igualmente, es el herbicida empleado en el Programa de Erradicación de Cultivos llícitos (2). Sin embargo, el uso de glifosato en el programa de aspersión de coca y amapola representa una fracción relativamente pequeña del total de su uso en Colombia (7).

El glifosato es un herbicida de amplio espectro, no selectivo y posemergente, cuya fórmula empírica es $\mathrm{C}_{3} \mathrm{H}_{8} \mathrm{NO}_{5} \mathrm{P}$, que corresponde a un ácido orgánico débil formado por una molécula de glicina y otra de fosfonometilo. Su forma física es un polvo cristalino, blanco, inodoro, con un peso específico de 1.704, soluble en agua e insoluble en solventes orgánicos y no tiene volatilización significativa (8). Ejerce su mecanismo de acción por inhibición de la enzima 5-enolpiruvil-shikimato-3-P sintetasa, esencial en el proceso de síntesis de los aminoácidos aromáticos en las plantas $(9,10)$.

El glifosato es adsorbido rápida y fuertemente por las partículas del suelo, lo cual impide su movilidad y su lixiviación, y lo inhabilita para ser absorbido a través de las raíces. Uno de los principales productos de la degradación por la acción bacteriana es el ácido amino-metilfosfónico, el cual es biodegradable y tiene una vida media de 30 días, aproximadamente. Al alcanzar el agua, el glifosato es absorbido por partículas en suspensión o en sedimentación para luego ser degradado, lo cual ocurre más lentamente que en los suelos, a causa del menor número de microbios; alcanza una vida media de 7 a 10 semanas en aguas naturales (11).

Los plaguicidas que contienen glifosato, como el Roundup®, están registrados en Colombia en la categoría toxicológica IV, ligeramente tóxicos, basados en la dosis letal $50\left(\mathrm{DL}_{50}\right)$ por vía oral del ingrediente activo en ratas, considerada mayor de $5.000 \mathrm{mg} / \mathrm{kg}$. Por tener toxicidad oral aguda y dérmica relativamente baja, ha sido clasificado por la Environmental Protection Agency, (EPA) en la categoría III (ligeramente tóxico) y en el grupo $E$ de oncogenicidad como no carcinogénico para humanos (12).

La toxicidad aguda $\left(\mathrm{DL}_{50}\right)$ para el glifosato comercial por vía oral y cutánea es mayor de $5.000 \mathrm{mg} / \mathrm{kg}$, y por inhalación, mayor de 3.400 $\mathrm{mg} / \mathrm{L}$ (13). Los estudios toxicocinéticos en animales de experimentación muestran una absorción de $30 \%$ a $36 \%$ en el tubo digestivo y una escasa absorción por vía cutánea. Una vez absorbido, se distribuye ampliamente en todo el organismo; $15 \%$ a $29 \%$ se excreta por la orina, $2 \%$ por el aire espirado y el $70 \%$ restante por las heces. Su metabolismo es escaso y $97 \%$ de la dosis oral se elimina como glifosato; su único metabolito es el ácido amino-metil-fosfónico, con una vida media de dos días, aproximadamente $(7,8)$.

Entre las manifestaciones clínicas por inhalación, puede causar irritación leve de la nariz y garganta, y al contacto con los ojos desencadena irritación ocular intensa, y con la piel, sensibilización, irritación leve y fotosensibilización (8).

Para el caso de la intoxicación aguda poringestión de glifosato como producto comercial, los síntomas aparecen según la dosis ingerida. Con la ingestión de 5 a $150 \mathrm{ml}$ se presentan síntomas leves, principalmente gastrointestinales, como 
náuseas, vómito, diarrea y dolor abdominal, que se resuelven en el lapso de 24 horas. Con ingestión de 20 a $500 \mathrm{ml}$, se presentan síntomas moderados gastrointestinales que duran más de 24 horas, como hemorragias gastrointestinales, esofagitis o gastritis verificables por endoscopia, y ulceración oral e hipotensión. En las intoxicaciones graves se puede presentar disfunción respiratoria, falla renal, falla cardiaca, coma y muerte (13-15).

El glifosato no fue mutagénico en ensayos de células mamíferas en sistemas in vitro e in vivo. Se ha informado sobre efectos nocivos en estudios de linfocitos humanos, los que mostraron que el glifosato produce cambios en el ADN de cromátides hermanas $(15,16)$ y, como principio activo, es mucho menos citotóxico para las células mononucleares de sangre periférica que la formulación comercial (16).

En cuanto a la teratogénesis y toxicidad para el embrión, en dosis superiores a $3.500 \mathrm{mg} / \mathrm{kg}$ diarios de glifosato, en ratas, se observó toxicidad para el desarrollo en forma de pérdida de la osificación del esternón y disminución del peso corporal total. Estas dosis también fueron tóxicas para las madres: el nivel de no efecto observable (NOEL) para el desarrollo y la toxicidad materna, fue de $1.000 \mathrm{mg} / \mathrm{kg}$ diarios. En un estudio sobre la reproducción en tres generaciones de ratas, a diferentes dosis, el hallazgo tóxico significativo fue dilatación tubular en los riñones de los recién nacidos de la primera generación de las madres que recibieron las dosis más altas $(30 \mathrm{mg} / \mathrm{kg}$ diarios); el NOEL para este efecto fue de $10 \mathrm{mg} /$ $\mathrm{kg}$ diarios (17-19).

Aunque ninguno de los estudios sobre mutagénesis requeridos para el registro del glifosato ha mostrado acción mutagénica, los resultados son diferentes cuando se realizan con formulaciones comerciales a base de glifosato. Por ejemplo, en estudios de laboratorio con varios organismos, se encontró que el Roundup $\AA$ incrementó la frecuencia de mutaciones letales recesivas ligadas al sexo en la mosca de la fruta. También, se ha reportado daño al ADN en pruebas de laboratorio con tejidos y órganos de ratón (20-22) y, de igual forma, no se ha asociado con incidencia de cáncer (23). Como antecedentes de investigación en el tema en Colombia, se tiene información de tres estudios descriptivos.

Uno fue realizado por Revelo et al. (24), "Efectos de la fumigación con glifosato en los municipios de Valle de Guamuez, San Miguel y Orito, Putumayo-Colombia, diciembre 2001", en el cual se hizo un análisis de la información consignada en los formatos de quejas, presentadas en la Personería Municipal de los municipios de Valle del Guamuez, San Miguel y suministrada por la Unidad de Asistencia Técnica de Orito.

En éste se encontró que $1.153(80 \%)$ de las 1.443 quejas presentadas ante las personerías de Valle del Guamuez, San Miguel y Orito hacen referencia a problemas de salud atribuidos a la aspersión. La frecuencia de síntomas referidos fue: brotes en piel (524), fiebre (516), cefalea (469), infección respiratoria aguda (454), diarrea (373), vómito (281), dolor abdominal (221), malestar general (179), mareos (137), angustia, miedo y pánico (64), dolor de garganta (41), conjuntivitis (32) y otros síntomas (30). Los porcentajes de cambio calculados en la morbilidad atendida en los meses de enero y febrero de 2000, comparados con el 2001, en el Hospital de La Hormiga, reportan un incremento estadísticamente significativo para eventos como fiebre, diarrea, dolor abdominal, infección respiratoria aguda e infecciones de piel $(p<0,005)(24)$.

El segundo estudio fue realizado por Uribe et al. y consistió en la revisión de las denuncias presentadas por la comunidad de Aponte en el noroccidente de Nariño, durante las aspersiones realizadasenel2000. Delas 29 quejas reportadas, se obtuvieron 21 historias clínicas que estaban disponibles en el Puesto de Salud de Aponte, en las cuales se encontraron diagnósticos de enfermedades de origen infeccioso o por otras causas no relacionadas con intoxicación por glifosato (25).

El tercer estudio, también llevado a cabo por Uribe et al., se realizó en los municipios del departamento del Putumayo, donde se practicó aspersión controlada de glifosato 
en diciembre de 2000 y febrero de 2001. En el estudio se observaron y midieron retrospectivamente los posibles efectos sobre la salud humana atribuibles a la exposición al glifosato y los posibles efectos por exposición a otros plaguicidas empleados para cultivar coca. Se encontró que los problemas de salud observados en los municipios objeto del estudio tuvieron una tasa de prevalencia similares a las encontradas en los reportes epidemiológicos de los años previos al inicio de las aspersiones. Las enfermedades referidas con mayor frecuencia por la población fueron gastrointestinales, cutáneas, oculares y respiratorias; sin embargo, las quejas en salud no se relacionaron con la localización de los sujetos en el momento de la aspersión. Igualmente, se encontró que los síntomas manifestados pueden tener su origen en la exposición crónica de la población a los múltiples productos agroquímicos empleados en los cultivos de coca en el departamento del Putumayo (25).

En ninguno de los estudios mencionados anteriormente se pudo establecer un nexo de causalidad entre los problemas de salud reportados y el Programa de Erradicación de Cultivos llícitos con Glifosato. Por ejemplo, muchos de los cuadros clínicos reportados no coinciden con las fechas en las que se efectuaron las aspersiones, mientras que las condiciones de salud reportadas corresponden con las condiciones endémicas de estas zonas. Por otra parte, los estudios realizados fueron de tipo retrospectivo, lo cual no permite establecer ni descartar una relación entre la exposición a una sustancia dada y las manifestaciones clínicas debidas a su exposición $(24,25)$.

El presente estudio tuvo como objetivo explorar los posibles efectos del glifosato y otros plaguicidas sobre la salud humana, como resultado de las aspersiones aéreas, mediante la detección de los posibles casos de intoxicación aguda por plaguicidas que se presenten en forma concomitante con la aplicación aérea de glifosato, la descripción de las manifestaciones clínicas de la exposición humana al glifosato, la caracterización de la exposición de la población de las áreas asperjadas a otros plaguicidas y la exploración de algunas actitudes de la población frente a las aspersiones aéreas.

Es de anotar que, en este estudio, no se evaluaron los impactos sociales, políticos, económicos ni ambientales de la medida, que podrían contribuir a la explicación de la gran mayoría de quejas.

\section{Materiales y métodos}

Se realizó un estudio descriptivo de corte transversal, en 112 individuos procedentes de las áreas asperjadas de los departamentos de Huila, Tolima, Putumayo, Guaviare, Santander, Antioquia, Magdalena y Guajira, que consultaron espontáneamente o se detectaron por búsqueda activa en los primeros cinco días de aplicada la medida, durante los años 2005-2006.

No se buscó en los departamentos objeto del proyecto un marco estadísticamente representativo, por dos razones fundamentales: la primera, porque el diseño del estudio no pretendía establecer relaciones de causalidad $y$, la segunda, por las dificultades operativas para la recolección de las muestras en los departamentos objeto del proyecto, dado que no se podía determinar con antelación cuántas personas podrían estar expuestas y, aunque se podían conocer las zonas asperjadas, pocas eran accesibles y seguras para el equipo investigador. La finalidad de esta investigación era documentar evidencias epidemiológicas y tomar decisiones futuras frente a las necesidades identificadas de desarrollar otros estudios.

Se incluyeron los casos que consultaron espontáneamente o que fueron referidos o detectados mediante búsqueda activa y que cumplieron con los siguientes criterios.

\section{Casos confirmados}

Criterios:

Clínico-epidemiológico: individuos procedentes de las zonas del Programa de Erradicación de Cultivos llícitos con Glifosato que presentaron durante los cinco días siguientes a la aspersión aérea, un cuadro clínico sugestivo de exposición a plaguicidas, diagnosticado por un médico y con claros antecedentes de exposición. 
De laboratorio: casos con indicadores biológicos de exposición o de efecto alterado debido a plaguicidas, con manifestaciones clínicas evidentes o sin ellas.

Dictamen médico-legal: persona fallecida con diagnóstico de intoxicación por plaguicida, confirmado mediante procedimientos médico-legales, exceptuando los casos de muerte intencional por suicido u homicidio.

La detección de los individuos se inició en el momento en que se aplicó la medida de la aspersión aérea. Los casos se captaron por medio de dos estrategias: la pasiva, que fueron los que consultaron a las Instituciones Prestadoras de Servicios de Salud y a las Empresas Sociales del Estado, y la búsqueda activa, realizada en campo directamente por el equipo de investigadores.

Se aplicó una encuesta con la cual se obtuvo información demográfica, antecedentes ocupacionales, toxicológicos, clínicos y percepción de los individuos ante el Programa de Erradicación de Cultivos llícitos con Glifosato. Se recolectaron muestras de orina y de sangre, máximo dentro de los primeros cinco días después de realizada la aspersión aérea. A cada individuo se le tomó una muestra de orina (aproximadamente, $50 \mathrm{ml}$ ), para la determinación de glifosato y de ácido aminometil-fosfónico, en frascos de polipropileno con tapa rosca, la cual se preservó congelada hasta su envío. Estas determinaciones se realizaron en el Centro Toxicológico de Quebec, Canadá. Asimismo, se recolectó una muestra de sangre $(10 \mathrm{ml})$ la cual se fraccionó tomando $9,5 \mathrm{ml}$ sin anticoagulante; esta muestra se centrifugó y el suero separado se transvasó a un tubo pyrex o similar, cuya boca se cubrió con papel de aluminio antes de enroscar, para análisis de plaguicidas organoclorados. Los sueros permanecieron refrigerados hasta su envío. Los $0,5 \mathrm{ml}$ restantes se envasaron en tubos eppendorf con heparina sódica como anticoagulante, para la determinación de la enzima acetilcolinesterasa. Estando las muestras en el laboratorio, se codificaron nuevamente con el fin de minimizar el sesgo del analista.

La determinación de acetilcolinesterasa y organoclorados se llevó a cabo en el Grupo de Salud
Ambiental-Investigación del Instituto Nacional de Salud. La determinación de organoclorados se realizó por extracción en fase sólida en discos $\mathrm{C} 18$ (SPED) en muestras de suero; posteriormente, se cuantificó por cromatografía de gases con detector de micro-captura de electrones (GC/ $\mu E C D)$, utilizando una columna cromatográfica HP-5. La enzima acetilcolinesterasa se determinó por la técnica de Limperos y Ranta $(26,27)$.

Los criterios de inclusión estuvieron definidos por los individuos que aceptaron participar voluntariamente y que refirieron presentar manifestaciones clínicas de exposición a plaguicidas, máximo dentro de los cinco días posteriores a las aspersiones aéreas, al igual que la aplicación de la encuesta y la toma de muestras biológicas dentro de este mismo periodo.

Se excluyeron del estudio: los individuos que interpusieron quejas cuya exposición ocurrió en un municipio de un departamento diferente a los incluidos en el proyecto; los que consultaron cinco días después de haber ocurrido las aspersiones en la zona; aquéllos seleccionados en el estudio, cuyas muestras no pudieron ser enviadas dentro de los cinco días posteriores a la toma; todos los individuos que voluntariamente no quisieron participar, y los individuos cuyas muestras llegaron al Instituto Nacional de Salud en neveras que estaban abiertas, con la cinta de enmascarar rota o cuyo contenido se había derramado por mal empaque en el transporte.

Se llevó a cabo el estudio piloto en el $10 \%$ del total de la población de estudio. Durante éste, se puso a prueba la encuesta, se valoró la pertinencia de las variables planteadas y se incorporaron las sugerencias dadas, haciendo los ajustes necesarios, tanto de instrumentos como de tiempos y movimientos. Las personas participantes en el estudio piloto no formaron parte de la población seleccionada en el estudio.

Antes de iniciar la recolección de la información y de las muestras biológicas, se les informó los objetivos del estudio, su importancia y los beneficios que les traería el participar. Una vez aceptaron voluntariamente su participación, firmaron un consentimiento escrito. 
Se construyó una base de datos en el programa Epi-Info, versión 6.04, y se realizó el análisis univariado de las variables de importancia epidemiológica. Igualmente, se empleó el programa Stata, versión 6.0, tanto para el análisis univariado como para el bivariado. Para este último, se cruzaron las principales variables que caracterizan la exposición con los resultados del seguimiento biológico. Con el fin de asegurar la calidad de la información, el $100 \%$ de las variables incluidas en la encuesta fueron revisadas para eliminar cualquier inconsistencia que se hubiera presentado en la fase inicial de digitalización.

En el cruce de las variables, se consideraron tablas de contingencia y se exploraron posibles asociaciones cuando fue de interés particular, mediante la prueba de ji al cuadrado o, en su defecto, mediante la prueba exacta de Fisher.

Este estudio fue aprobado por el Comité Técnico de Investigación y el Comité de Ética del Instituto Nacional de Salud.

\section{Resultados}

Se incluyeron en el estudio 112 personas habitantes de zonas donde fue aplicado el Programa de Erradicación de Cultivos llícitos con Glifosato, en 12 municipios de 8 departamentos. A las 112 personas entrevistadas se les realizó una encuesta y se les recolectaron muestras biológicas. Durante el transporte, 6 muestras de orina recolectadas por el grupo de investigadores se perdieron por derrame de las mismas, con una pérdida de $5,4 \%$, por lo que el total de muestras analizadas para glifosato y ácido amino-metilfosfónico fue de 106.

A algunos individuos captados de manera espontánea en diferentes unidades hospitalarias, no les fueron tomadas las muestras de sangre para el análisis de plaguicidas organosforados, carbamatos y organoclorados, por lo cual se tuvo una pérdida de $7,1 \%$ y se analizaron en total 104 muestras.

El 92,9\% (104) de las muestras fueron obtenidas directamente porelgrupoinvestigadordel Instituto Nacional de Salud, mediante desplazamientos a las áreas asperjadas. En el departamento de Putumayo, se recolectaron 46 muestras (41,1\%); en Guaviare, 20 (17,9\%); en Antioquia, $18(16,1 \%)$; en La Guajira, $17(15,2 \%)$, y en Magdalena, 3 (2,6\%), con el acompañamiento de funcionarios de las respectivas direcciones de salud. El 7,1\% (8) restante fueron captadas de manera espontánea en algunas de las unidades hospitalarias, se recolectaron 3 muestras $(2,7 \%)$ en el departamento del Huila, $2(1,7 \%)$ en Santander, $2(1,7 \%)$ en Magdalena y $1(1,0 \%)$ en Tolima. 2

El $99,0 \%$ de los casos del estudio procedían del área rural; sólo un caso $(1,0 \%)$ manifestó vivir en la zona urbana, aunque todas las exposiciones fueron rurales. El 56,3\% (63) eran hombres, quienes en una mayor proporción estuvieron expuestos a la medida de aspersión aérea por su vinculación a las actividades agrícolas. El restante $43,7 \%$ (49) pertenecían al sexo femenino y fueron expuestas de forma casual.

El promedio de edad fue de 32 años (rango, 2 a 78; $D E=16$ ) para los dos sexos; no se encontró una diferencia estadísticamente significativa entre la edad y el sexo $(p=0,141)$. La población estudiada fue predominantemente joven y se concentró en tres grupos, el de 30 a 34 años $(16,1 \%)$, el de 35 a 39 años $(13,4 \%)$ y el de 15 a 19 años (11,6\%). La proporción más baja de la población fue la menor de 15 años y la mayor de 50 años representó el 13,5\%. La principal ocupación de la población fue la agrícola, 51,0\% (57), seguida de las actividades domésticas, $32,0 \%$ (36), y en tercer lugar estuvieron los estudiantes, $8,0 \%$ (9). El 37,5\% (42) de la población se había empleado como jornaleros en los 15 días anteriores a la entrevista, el 32,1\% (36) realizaba oficios de la casa, el 10,7\% (12) eran empleados, el $8,1 \%$ (9) eran trabajadores independientes, el 7,1\% (8) eran estudiantes y el restante $4,5 \%$ (5) se dedicaba a actividades recreativas.

El 45,0\% (51) de la población estudiada se encontraba afiliada al régimen contributivo del Sistema General de Seguridad Social en Salud, el 36,0\% (40) no tenía ninguna afiliación, el $18,0 \%$ (20) correspondía al régimen subsidiado y sólo un 1,0\% (1) refirió ser atendido en salud 
de manera particular. Se encontró una población joven que en el $50,0 \%$ (56) no había terminado la educación primaria y sólo el 25,0\% (28) la había completado; hubo porcentajes muy bajos de educación secundaria: el 2,6\% (3) no la terminó y el 4,5\% (5) era bachiller; tan sólo el 1,8\% (2) tenía una educación universitaria. El porcentaje de población analfabeta fue de 16,1\% (18).

\section{Caracterización de la exposición}

Se indagó sobre la exposición de los individuos en el momento en que se llevaron a cabo las aspersiones aéreas con glifosato. El $71,4 \%$ (80) de los casos manifestó que la forma de exposición fue por el aire y el 38,4\% (43) refirió que tuvo contacto directo con la mezcla al caerle durante la aspersión; el 5,4\% (6) restante tuvo exposición por alguna fuente de agua. No se halló exposición por alimentos u otra fuente.

En relación con el abastecimiento de agua para consumo humano, se encontró que 24,1\% (27) recogía el agua lluvia, el 19,6\% (22) la obtenía de un pozo o aljibe, el 50,0\% (56) del río o quebrada, el 1,0\% (1) del acueducto y el 5,3\% (6) restante de otras fuentes, incluidos pequeños acueductos, lo cual indica la ruralidad de la población estudiada y la carencia de sistemas de acueducto en las zonas.

El 25,9\% (29) de los individuos incluidos en el estudio informaron que en el momento de la exposición se hallaban realizando actividades propias del hogar, el $20,5 \%$ (23) en actividades recreativas, el $17,0 \%$ (19) cultivando, el $11,6 \%$ (13) en el trabajo habitual, el 7,1\% (8) caminando por la zona asperjada y el $17,9 \%$ (20) restante realizando diferentes labores.

\section{Historia ocupacional}

El 50,0\% (56) de la población refirió el uso de plaguicidas en su trabajo, y se encontraron 45 nombres comerciales de agroquímicos. En el cuadro 1 se citan los 10 más utilizados, con un promedio de uso de 3,6 plaguicidas por persona. El tiempo que llevaban utilizando los plaguicidas fue, en promedio, de 84,8 meses (rango, 2 a $480 ; \mathrm{DE}=105,3)$ y refirieron aplicar plaguicidas en promedio 5,6 horas al día (rango, 1 a 12; $\mathrm{DE}=2,8)$.

En relación con las labores realizadas durante el periodo que no están empleando plaguicidas, 23 $(41,1 \%)$ individuos refirieron estar desyerbando, $19(33,9 \%)$ cultivando, $9(16,1 \%)$ realizando oficios del hogar y 5 (8,9\%) en diferentes actividades.

Los principales nombres comerciales de los plaguicidas empleados fueron: Gramoxone $\AA$, Tamaron $\AA$, Roundup $\AA$, Aniki $(\AA$, Panzer $\AA$, Furadan $\AA$ y Metil-paratión $\AA$, entre otros. La dosis letal 50 de los ingredientes activos de los diez plaguicidas más utilizados reportados por los

Cuadro 1. Distribución de plaguicidas empleados por nombre comercial, categoría toxicológica, organismos que controla y grupo químico, Colombia 2006.

\begin{tabular}{lcclcc}
\hline $\begin{array}{l}\text { Nombre } \\
\text { comercial }{ }^{\circledR}\end{array}$ & $\begin{array}{c}\text { Categoría } \\
\text { toxicológica }\end{array}$ & $\begin{array}{c}\text { Tipo de organismo } \\
\text { que controlan }\end{array}$ & Grupo químico & N & $\%$ \\
\hline Gramoxone & I & Herbicida & Bipiridilo & 29 & 25,9 \\
Tamaron & I & Insecticida & Organofosforado & 20 & 17,9 \\
Roundup & IV & Herbicida & N-fosfonometil- glicina & 18 & 16,1 \\
Anikil & II & Herbicida & Clorofenol & 8 & 7,1 \\
Panzer & IV & Herbicida & N-(fosfonometil) glicina & 7 & 6,3 \\
Furadan & I & Insecticida & Carbamato & 7 & 6,3 \\
Metil paratión & I & Insecticida & Organofosforado & 7 & 6,3 \\
Glifosato & IV & Herbicida & N-fosfonometil- glicina & 6 & 5,4 \\
Manzate & III & Fungicida & Ditiocarbamato & 5 & 4,5 \\
Gramafin & I & Herbicida & Bipiridilo & 5 & 4,5 \\
& & & Total & 112 & 100 \\
\hline
\end{tabular}

Fuente: Encuesta individual, Instituto Nacional de Salud, 2006 
Cuadro 2. Dosis letal 50 (DL50) de los plaguicidas reportados por los individuos del estudio, Colombia, 2006.

\begin{tabular}{lll}
\hline Nombre comercial® & Ingrediente activo & \multicolumn{1}{c}{$\begin{array}{c}\text { DL50 } \\
\text { cutánea }\end{array}$} \\
\hline Gramoxone & & $236 \mathrm{mg} / \mathrm{kg}$ para conejos \\
Tamaron & Paraquat & $130 \mathrm{mg} / \mathrm{kg}$ para ratas \\
Roundup & Metamidofos & $5.000 \mathrm{mg} / \mathrm{kg}$ para conejos \\
Anikil & Glifosato & $>2.000 \mathrm{mg} / \mathrm{kg}$ para conejos \\
Panzer & $2,4-D($ éster butílico) & $5.000 \mathrm{mg} / \mathrm{kg}$ para conejos \\
Furadan & Glifosato & $>3.000 \mathrm{mg} / \mathrm{kg}$ para ratas \\
Metil paratión & Carbofuran & $50 \mathrm{mg} / \mathrm{kg}$ para ratas \\
Glifosato & Metil paratión & $5.000 \mathrm{mg} / \mathrm{kg}$ para conejos \\
Manzate & Glifosato & $>5.000 \mathrm{mg} / \mathrm{kg}$ para conejos \\
Gramafin & Mancozeb & $236 \mathrm{mg} / \mathrm{kg}$ para conejos \\
\hline
\end{tabular}

Fuente: United States Environmental Protection Agency (30)

individuos del estudio, se muestra en el cuadro 2. El $45,0 \%$ (90) fueron herbicidas; $44,0 \%(88)$, insecticidas, y $11,0 \%$ (22), fungicidas.

Los plaguicidas usados por la población de estudio fueron de categoría I, extremadamente tóxicos, 45,5\% (92), seguidos de los de la categoría III, moderadamente tóxicos, $22,8 \%$ (46), la categoría IV, ligeramente tóxicos, 19,3\% (39) y, por último, la categoría II, altamente tóxicos, $12,4 \%(25)$.

La distribución de los plaguicidas por categoría toxicológica se presenta en el cuadro 3. Entre los plaguicidas de categoría toxicológica IV, ligeramente tóxicos, el herbicida glifosato fue el más utilizado, tal como se reporta en la literatura mundial. Todos los productos con los nombres comerciales anotados en el cuadro 3 para esta categoría, tienen como principio activo $\mathrm{N}$-fosfonometil-glicina. En general, la población no reconoce que las sustancias que usan contienen el mismo ingrediente activo que se emplea en las aspersiones aéreas, es decir, el herbicida glifosato.

Pese a que los organoclorados fueron prohibidos en el país, se reportó el uso de los insecticidas tionil y tiodán. Los organofosforados fueron el grupo químico de mayor uso en la población de estudio, 29,2\% (59), y éste es el grupo que más intoxicaciones agudas causa en el país $(28,29)$.

En segundo lugar, la $\mathrm{N}$-fosfonometil-glicina, $19,3 \%$ (39), seguida de los bipiridilos, 16,8\% (34), y los carbamatos, $10,4 \%$ (21), entre otros.
Cuadro 3. Distribución de plaguicidas empleados por categoría toxicológica, Colombia, 2006

\begin{tabular}{clrr}
\hline $\begin{array}{c}\text { Categoría } \\
\text { toxicológica }\end{array}$ & $\begin{array}{c}\text { Nombre } \\
\text { comercial }{ }^{8}\end{array}$ & No. & $\%$ \\
\hline I & Gramoxone & 29 & 31,5 \\
& Tamarón & 20 & 21,7 \\
& Metil paratión & 7 & 7,6 \\
& Furadan & 7 & 7,6 \\
II & Gramafin & 5 & 5,4 \\
& Aniquil & 8 & 14,3 \\
& Puntouno & 4 & 7,1 \\
& Cipermetrina & 3 & 5,4 \\
& Paredón & 2 & 3,6 \\
III & Látigo & 1 & 1,8 \\
& Elsan & 1 & 1,8 \\
& Manzate & 5 & 10,9 \\
& Lorsban & 5 & 10,9 \\
IV & Sevin & 4 & 8,7 \\
& Malatión & 4 & 8,7 \\
& Glifosato & 4 & 10,7 \\
& Roundup & 12 & 32,1 \\
& Panzer & 5 & 12,5 \\
& Faena & 3 & 7,1 \\
& Socar & 1 & 3,6 \\
& Estelar & 1 & 3,6 \\
\hline
\end{tabular}

Fuente: Encuesta individual, Instituto Nacional de Salud, 2006

Respecto a la capacitación sobre el manejo seguro de los plaguicidas, sólo 11 (19,6\%) de los que utilizaban plaguicidas refirieron haberla recibido alguna vez en su vida.

Entre las 56 personas que utilizaban plaguicidas, $55,4 \%$ (31) tenía la costumbre de almacenarlos fuera de la casa, $23,2 \%$ (13) lo guardaba dentro de la casa y $21,4 \%$ (12) disponía de un 
área exclusiva para su almacenamiento. Los recipientes fueron destinados para almacenar agua, $1,8 \%$ (1); quemados, $35,7 \%$ (20); enterrados, $16,1 \%$ (9); utilizados para guardar otros plaguicidas, 7,1\% (4); botados a campo abierto, $35,7 \%$ (20), y un porcentaje bajo, $1,8 \%$ (1), arrojados al agua.

La protección personal era precaria. Del total de personas que utilizaban plaguicidas (56), 96,4\% (54) no empleaba uniforme en esta actividad; la labor de fumigación la realizan con la misma ropa de uso diario. No se reportó protección ocular con visores o monogafas; sólo el 5,4\% (3) usaba protección en los miembros superiores (guantes cortos), 7,2\% (4) refirió tener alguna protección respiratoria con tapabocas o mascarilla y, para la protección del cuerpo, 5,4\% (3) empleaba camisa; el elemento más utilizado fueron las botas de caña alta y caña baja, 66,1\% (37).

En relación con las medidas de higiene, 64,3\% (36) utilizaba para las aplicaciones la misma ropa de trabajo que empleaba en sus actividades habituales y $91,1 \%$ (51) se cambiaba la ropa y se bañaba al finalizar la jornada laboral; 89,3\% (50) se cambiaba diariamente, $8,9 \%$ (5) dos veces a la semana y el resto, una vez a la semana. La mitad de la población que trabajaba con plaguicidas lavaba la ropa contaminada en sus casas y el restante $50 \%$ la lavaba en caños, quebradas y ríos. El 48,2\% (27) la lavaba mezclada con el resto de la ropa de la familia.

Respecto a los hábitos, 46,4\% (26) de los trabajadores se alimentaba en el cultivo; de éstos, $65,4 \%$ (17) lo hacía siempre y $34,6 \%$ (9) ocasionalmente. El $73,1 \%$ (19) se lavaba las manos siempre antes de ingerir los alimentos, $15,4 \%$ (4) lo hacía ocasionalmente y $11,5 \%$ (3) de los entrevistados nunca lo hacía. Del total de personas incluidas en el estudio, 19 (17,0\%) fumaba y $46(41,1 \%)$ consumía licor; de las que fumaban, $9(47,4 \%)$ lo hacía dentro del cultivo, con una frecuencia de 6 a 10 cigarrillos al día. De los individuos que reportaron consumir licor, $19,6 \%$ (9) lo hacía una vez a la semana y el mismo porcentaje refirió ingerirlo dos veces al mes; igualmente, 43,5\% (20) lo hacía ocasionalmente.
De las 112 personas entrevistadas, 12,5\% (14) manifestó haberse intoxicado con plaguicidas alguna vez en su vida; $57,2 \%$ (8) de éstas, utilizó remedios caseros, $35,7 \%$ (5) consultó al médico y $7,1 \%$ (1) no hizo nada al respecto. El plaguicida reportado como el que mayores intoxicaciones causó, fue el Furadan® $(37,5 \%)$, seguido por el Tamaron $\AA$ (28,6\%), el Lannate® $(14,3 \%)$, el Lorsban® y el Metavin $\AA(7,1 \%)$.

\section{Actitud frente al Programa de Erradicación de Cultivos llícitos con Glifosato}

De igual forma, se indagó sobre la percepción individual del Programa de Erradicación de Cultivos llícitos con Glifosato. Se reportó que sólo $7,1 \%$ (8) creía que es una política de Estado que debe realizarse. El 68,7\% (77) de los encuestados pensaba que las aspersiones podían producir efectos sobre la salud, $67,0 \%$ (75) que afectaban los cultivos lícitos; $52,7 \%$ (59), el medio ambiente; 51,8\% (58), los animales; $42,9 \%$ (48), la economía, y un porcentaje mínimo no respondieron $(0,9 \%)$. Igualmente, se les preguntó de sus sentimientos acerca de las aspersiones, y se obtuvo que la mayor impresión fue la tristeza $(61,6 \%)$, seguido de la desesperanza $(25,0 \%)$, las ganas de irse $(23,2 \%)$, el rechazo $(15,2 \%)$, el miedo y la depresión (14,3\%).

\section{Manifestaciones clínicas}

En el cuadro 4 se describen los sistemas en los cuales previamente se agruparon los síntomas reportados por los individuos que conformaron el estudio. La mayoría de síntomas reportados se relacionan principalmente con alteraciones neurológicas y de piel. En cuanto a las alteraciones neurológicas, 82,2\% (92) manifestó algún síntoma, y los principales fueron cefalea, $37,5 \%$ (42), mareo, 9,8\% (11), y sudoración profusa y visión borrosa, 7,1\% (8). Entre las manifestaciones de piel, $71,5 \%$ (80) refirió alguna de ellas; el prurito, 35,7\% (40), y el eritema, $20,5 \%$ (23), fueron las más mencionadas.

Los otros sistemas implicados en la mayoría de las manifestaciones clínicas fueron el sistema digestivo, $68,8 \%$ (77), y los órganos de los sentidos, $42,9 \%$ (48). Es importante aclarar 
que cada persona pudo haber mencionado más de una manifestación clínica al momento de realizarle la encuesta.

\section{Biomarcadores de exposición y efecto}

Respecto a los biomarcadores de exposición $y$ de efecto que se emplearon en el estudio, en el cuadro 5 se muestran los resultados para glifosato y su metabolito, ácido aminometil-fosfónico, teniendo en cuenta el límite de detección y de cuantificación del método cromatográfico. Es de aclarar que el límite de detección para glifosato es $0,5 \mu \mathrm{g} / \mathrm{L}$, es decir, por debajo de este límite el equipo no tiene la capacidad de detectar concentraciones de glifosato. Por encima de este límite, se puede detectar que existe alguna concentración de glifosato, pero no siempre se puede cuantificar. El límite de cuantificación para glifosato es de 2 $\mu \mathrm{g} / \mathrm{L}$, por debajo del cual se puede detectar pero

Cuadro 4. Manifestaciones clínicas reportadas por los individuos incluidos en el estudio agrupadas por sistemas, Colombia, 2006.

\begin{tabular}{lcc}
\hline Sistemas & N & $\%$ \\
\hline Neurológico & 92 & 82,2 \\
Piel & 80 & 71,5 \\
Digestivo & 77 & 68,8 \\
Órganos de los sentidos & 48 & 42,9 \\
Respiratorio & 25 & 22,3 \\
Hematopoyético & 24 & 21,5 \\
Cardiovascular & 10 & 9,0 \\
Urinario & 4 & 3,6 \\
\hline
\end{tabular}

Fuente: Encuesta individual, Instituto Nacional de Salud, 2006 no cuantificar, y por encima de este límite se puede cuantificar $y$, por lo tanto, hay la certeza de que se encuentra glifosato en la muestra de orina analizada. Lo mismo sucede con el ácido amino-metil-fosfónico, cuyo límite de detección es de $1 \mu \mathrm{g} / \mathrm{L}$ y el de de cuantificación es de 15 $\mu \mathrm{g} / \mathrm{L}$.

El valor promedio de las concentraciones de glifosato en orina fue de 7,6 $\mu \mathrm{g} / \mathrm{L}$, con un rango de 0 a $130 \mu \mathrm{g} / \mathrm{L}$ y una desviación estándar (DE) de 18,6, y para ácido amino-metil-fosfónico, el promedio fue de $1,6 \mu \mathrm{g} / \mathrm{L}$, con un rango de 0 a $56 \mu \mathrm{g} / \mathrm{L}$ y una DE de 8,4 .

En relación con el glifosato, se encontró que en $60,4 \%(64)$ de las muestras de orina analizadas no se detectó este herbicida y en $39,6 \%$ (42) sí se detectó. La totalidad de muestras en las cuales se detectó glifosato fue igualmente cuantificada. Para el ácido amino-metil-fosfónico, 96,2\% (102) de las muestras no fueron detectadas y $3,8 \%$ (4) fueron detectadas; asimismo, el total de muestras detectadas fueron cuantificadas.

De los 42 individuos que tuvieron niveles de glifosato cuantificables, $4(9,5 \%)$ presentaron niveles de ácido amino-metil-fosfónico cuantificables; estos últimos tenían niveles de glifosato de $58,8 \mu \mathrm{g} / \mathrm{L}$ en promedio, con un rango de 28 a $130 \mu \mathrm{g} / \mathrm{L}$.

Del total de individuos con niveles cuantificables de glifosato, $27(64,3 \%)$ reportaron el uso de este herbicida con cualquiera de sus diferentes nombres comerciales en actividades agrícolas

Cuadro 5. Resultados de glifosato y ácido amino-metil-fosfónico en orina de los individuos incluidos en el estudio, Colombia, 2006.

\begin{tabular}{llrr}
\hline Glifosato & Valores & $\mathbf{N}$ & $\%$ \\
\hline Límite de detección: $0,5 \mu \mathrm{g} / \mathrm{L}$ & No detectado & 64 & 60,4 \\
& Detectado & 42 & 39,6 \\
Límite de cuantificación: $2 \mu \mathrm{g} / \mathrm{L}$ & Detectado no cuantificado & 0 & 39,6 \\
\hline Ácido amino-metil-fosfónico & Cuantificado & 42 & $\%$ \\
\hline Límite de detección: $1 \mu \mathrm{g} / \mathrm{L}$ & Valores & $\mathbf{N}$ & 96,2 \\
Límite de cuantificación: $15 \mu \mathrm{g} / \mathrm{L}$ & No detectado & 102 & 3,8
\end{tabular}

Fuente: Centro Toxicológico de Québec (Canadá), 2006 
$y$, de los 4 con niveles cuantificables de ácido amino-metil-fosfónico, 2 (50\%) reportaron el uso de glifosato como ingrediente activo en labores agrícolas.

El departamento de Putumayo presentó el mayor número de individuos a quienes se les detectó tanto glifosato (23) como ácido amino-metilfosfónico (4) en orina, seguido por Guaviare (10), La Guajira (5) y Antioquia (4).

La determinación de la enzima acetilcolinesterasa se empleó como biomarcador de efecto por exposición a plaguicidas organofosforados y carbamatos. De todos los individuos participantes en el estudio, $91,3 \%$ (95) presentó valores mayores o iguales a $75 \%$, y $8,7 \%$ (9), valores menores a $75 \%$, de los cuales, $7,1 \%$ (8) tuvieron valores de $62,5 \%$ y un solo individuo presentó un valor de inhibición de la acetilcolinesterasa del $50 \%$. Todos los trabajadores que tuvieron valores anormales se encontraron en un rango de $50 \%$ a $62,5 \%$, que indica probable sobreexposición; no se encontró ningún valor entre $25 \%$ y $37,5 \%$, que representa una sobreexposición seria, ni entre $0 \%$ y $12,5 \%$, que muestra sobreexposición muy seria y peligrosa. Por la técnica de Limperos y Ranta, los porcentajes iguales o mayores de $75 \%$ de inhibición de la enzima acetilcolinesterasa son normales y los menores a $75 \%$ se consideran anormales. De todo el grupo de estudio, en 8 no fue posible tomar la muestra de sangre para la determinación de acetilcolinesterasa.

Putumayo fue el departamento que presentó el mayor porcentaje $(77,8 \%)$ de individuos con inhibición de la acetilcolinesterasa.

Igualmente, se realizaron las determinaciones para 13 plaguicidas organoclorados en suero. Es importante aclarar que los derivados clorados tienen diferentes estructuras químicas que se pueden clasificar de la siguiente manera:

DDT y compuestos análogos: DDT, DDE, metoxicloro y dicofol, entre otros.

Hexacloro ciclohexano y compuestos ánalogos: HCB y el lindano.

Ciclodienos: aldrín, dieldrín, endrín, isodrín, telodrín y endosulfán.
Lindenos clorados: clordano, heptacloro y nonaclor.

Terpenos o canfenos policlorados: toxafeno y strobane (28)

Hay que tener en cuenta que una persona puede tener más de un metabolito. De todos los plaguicidas analizados, el heptacloro fue el que se presentó con mayor frecuencia, $64,3 \%$ (72), seguido del 4,4-DDE (metabolito del DDT), $17,0 \%$ (19); el aldrín, 14,3\% (16); el gammahexaclorobenceno, $10,7 \%$ (12), y el alfahexaclorobenceno, 8,9\% (10). Teniendo en cuenta la cantidad encontrada de estos plaguicidas al ser analizados en suero, el heptacloro mostró el promedio más alto, $9,1 \mathrm{ng} / \mathrm{L}$, y un rango de 0 a 43,8, seguido por el 4,4-DDT, 5,9 ng/L, y un rango de 0 a 284,9. El departamento con mayor frecuencia de casos con niveles de plaguicidas organoclorados en suero fue Putumayo, seguido por Guaviare y La Guajira.

\section{Análisis bivariado}

Se realizó el análisis bivariado entre los diferentes valores de los biomarcadores empleados y las variables incluidas en la encuesta.

La edad fue estratificada en tres grupos de 2 a 14 años, de 15 a 44 años y de 45 a 78 años; se halló que en el grupo de 15 a 44 años estuvo el mayor porcentaje $(40,2 \%)$ de individuos que trabajaba con plaguicidas, con una asociación estadísticamente significativa $(p<0,005)$.

Relación de variables con los niveles de glifosato y su metabolito, ácido amino-metilfosfónico, en orina

Los resultados de glifosato y ácido amino-metilfosfónico cuantificado fueron relacionados con los elementos de protección personal y las medidas de higiene industrial, como cambio de ropa y ducharse el cuerpo al finalizar la jornada laboral, lavarse las manos antes de ingerir los alimentos y consumir alimentos en el sitio de trabajo, entre otras. Aunque son 56 las personas que refirieron el uso de plaguicidas, a tres de ellas no fue posible analizarles glifosato y el ácido amino-metil-fosfónico en orina, por lo que el análisis se efectúo con 53 personas. No se 
encontró ninguna asociación estadísticamente significativa entre elementos de protección personal y las medidas de higiene industrial ( $p>0,005)$, y los niveles de glifosato en orina. Para la determinación del ácido amino-metilfosfónico cuantificado en orina se encontró una asociación entre esta variable y el no uso de tapabocas desechable $(p=0,001)$, al igual que con el uso de camisa manga larga $(p<0,005)$.

Los resultados de los niveles de glifosato y ácido amino-metil-fosfónico cuantificados y la sintomatología reportada en las encuestas, no mostraron una asociación estadísticamente significativa $(p>0,005)$. Sin embargo, los síntomas que con mayor frecuencia reportaron los individuos que tenían valores de glifosato y ácido amino-metil-fosfónico cuantificables fueron cefalea, seguida por ardor ocular, fiebre, mareo y sequedad en la piel. Teniendo en cuenta que no se encontró una asociación estadísticamente significativa entre cada una de las manifestaciones clínicas y los niveles de glifosato y ácido amino-metil-fosfónico cuantificados, se agruparon los síntomas por sistemas, y tampoco se halló relación.

No se encontró asociación estadísticamente significativa entre antecedentes toxicológicos, como fumar, consumir licor o haberse intoxicado, con los niveles de glifosato ( $p>0,005)$; pero, en cambio, el antecedente de intoxicación con plaguicidas y niveles de ácido amino-metilfosfónico cuantificados en orina si presentó asociación $(p=0,027)$.

Tal como se observa en el cuadro 6 , se encontró una relación estadísticamente significativa entre el uso de glifosato terrestre (manual) y los niveles de este herbicida en orina (OR=2,54; IC95\% 1,08-6,08), mientras que para el ácido amino- metil-fosfónico no hubo una relación significativa (OR=0,24; IC95\% 0,02-4,47).

En relación con la vía de exposición, 33 (78,6\%) de los individuos que tenían glifosato cuantificado refirieron como vía de exposición la aérea $(p=0,346)$ y $16(38,1 \%)$, la dérmica $(p=0,294)$. Las mismas vías se reportaron en quienes se detectó el metabolito ácido amino-metilfosfónico, $4(100 \%)$ por vía aérea $(p=0,222)$ y 2 $(50 \%)$ por vía dérmica $(p=0,816)$. Sin embargo, no se encontró asociación entre estas variables $(p>0,005)$.

\section{Relación de variables con los niveles de acetilcolinesterasa en sangre}

Se estudio la relación de las variables edad, sexo y vía de exposición a plaguicidas con los niveles de acetilcolinesterasa, sin que se encontrara una asociación significativa ( $p>0,005)$.

En cuanto al uso de elementos de protección personal y las medidas de higiene industrial con los niveles de acetilcolinesterasa, no se encontró una diferencia significativa entre los que tienen dichos niveles normales y anormales.

La cefalea $(39,5 \%)$ y el ardor ocular $(23,7 \%)$ fueron las manifestaciones clínicas que con mayor frecuencia reportaron los individuos con niveles de acetilcolinesterasa anormal. Sólo se encontró una asociación estadísticamente significativa entre el aumento de los valores de acetilcolinesterasa y la resequedad de piel $(p=0,046)$ y el ardor ocular $(p=0,003)$.

\section{Relación de las diferentes variables con los niveles en suero de los plaguicidas organoclorados}

Al relacionar el uso de elementos de protección personal y las medidas de higiene industrial

Cuadro 6. Relación entre los niveles de glifosato y AMPA y el uso de este herbicida terrestre (manual), Colombia, 2006.

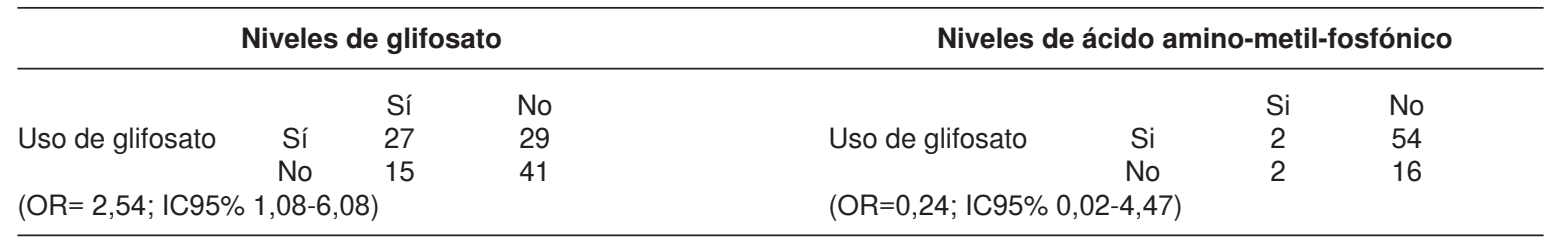

Fuente: Encuesta individual, Instituto Nacional de Salud, 2006 
con la presencia de organoclorados en suero, no se encontró asociación entre estas variables ( $p>0,005)$. Sin embargo, un alto porcentaje de los individuos con organoclorados en las muestras de suero, trabajaba con la ropa de calle $(85,7 \%)$, la cambiaban al finalizar la jornada laboral $(80,3 \%)$ y se duchaban al terminar la misma $(82,1 \%)$, pero no empleaban ningún elemento de protección personal al usar este tipo de plaguicidas altamente liposolubles.

La presencia o ausencia de organoclorados se relacionó con cada una de las manifestaciones clínicas reportadas en el estudio; sin embargo, no se encontró asociación con ninguna de ellas, ni tampoco cuando las manifestaciones se agruparon por sistemas.

\section{Discusión}

Los estudios en poblaciones humanas expuestas a agentes ambientales nocivos para la salud, constituyen en la actualidad el objeto de numerosas investigaciones epidemiológicas y toxicológicas, partiendo del hecho de que cualquier exposición a productos potencialmente peligrosos debe ser evitada en la medida de lo posible; sin embargo, no hay que desconocer que numerosos individuos por razones de su trabajo están en contacto directo con productos químicos, en quienes se incrementa la probabilidad de sufrir efectos adversos sobre su salud (29).

El herbicida glifosato se utiliza ampliamente en la agricultura y para la erradicación de la coca y la amapola. En Colombia se estima que de $10 \%$ a $14 \%$ del uso total es para el programa de erradicación (7). Los hallazgos de esta investigación corroboran los resultados de otros estudios (7) sobre la amplia utilización de los plaguicidas y de otras sustancias empleadas, tanto en la producción de coca y amapola como en la agricultura; $y$, más allá del objetivo mismo, el estudio permitió confirmar el amplio uso del glifosato en la población y tener un panorama real de la problemática del uso indiscriminado de plaguicidas en ocho departamentos del país.

Todos los individuos (112) incluidos en el estudio vivían en zonas donde fue aplicado el Programa de Erradicación de Cultivos llícitos con Glifosato, y Putumayo fue el departamento donde se recolectó el mayor número de muestras. El $99,0 \%$ de los individuos del estudio procedía de la zona rural y sólo una persona manifestó vivir en zona urbana, aunque la exposición a glifosato se produjo en el área rural; de éstos, el mayor porcentaje pertenecía al sexo masculino $(56,3 \%)$, con un rango de edad muy amplio que osciló entre los 2 y los 78 años. En el grupo de edad de 30 a 34 años se presentó el mayor porcentaje de los individuos estudiados, lo que indica que es población laboralmente activa y que son los adultos jóvenes los que más se emplean en las actividades de cultivos ilícitos.

La tercera parte de los individuos manifestó no tener ninguna afiliación al SGSSS (36,0\%). Lo anterior puede deberse a que la mayoría de trabajadores labora informalmente y no tiene un contrato de trabajo. El 45,0\% de la población refirió estar afiliada al régimen contributivo, lo que les permite acceder a la atención en salud.

La proporción de población afiliada al régimen contributivo (45,5\%) fue mayor a la que no tenía ninguna afiliación al SGSSS (36,0\%) y, aunque no se puede explicar lo primero, lo segundo es un indicador de la condición de informalidad laboral. El porcentaje restante (17,8\%) pertenece al régimen subsidiado y sólo $0,9 \%$ es atendido de forma particular.

Entre los individuos encuestados se encontró un porcentaje alto de población que refirió ser analfabeta, cifra que superó al promedio nacional que es del $13,0 \%$. Es importante resaltar que $50,0 \%$ de la población no había terminado la educación primaria.

Un alto porcentaje de las personas que conformaron la muestra manifestaron que la forma como se expusieron al glifosato fue por el aire, seguida por el contacto directo que tuvieron con el herbicida en el momento de la aspersión. Lo anterior se confirma ya que la población mencionó haber estado realizando actividades como cultivar y caminar por la zona asperjada, lo que evidencia la exposición durante las aspersiones aéreas.

El $51,0 \%$ de la población estudiada realiza actividades agrícolas, $50,0 \%$ utiliza plaguicidas y 
$37,5 \%$ se había empleado como jornalero en los 15 días anteriores a la entrevista, oficio en el cual puede haber mayor probabilidad de exposición a plaguicidas; por lo tanto, la exposición de estos individuos no es exclusivamente por las aspersiones aéreas que realiza el Programa de Erradicación de Cultivos llícitos con Glifosato, sino por exposición ocupacional. Estos trabajadores agrícolas se dedican a varios tipos de cultivos, entre ellos la coca; por ende, las necesidades en función del control de plagas y enfermedades del cultivo son diferentes y conlleva a la utilización de gran cantidad de productos, incluso al empleo de mezclas complejas de diferentes compuestos sin atender ninguna fórmula o medida. Lo anterior se corrobora con el hallazgo de 45 nombres comerciales de agroquímicos y que $50,0 \%$ de la población refirió el uso de plaguicidas en su trabajo por un tiempo prolongado que, en promedio, fue de 7 años y 8 meses, lo que se considera como una exposición crónica que pudiera desencadenar efectos a largo plazo.

Los herbicidas fueron el principal grupo de plaguicidas utilizado por la población que realiza actividades agrícolas, seguido por los insecticidas y fungicidas, datos que concuerdan con los productos registrados por el Instituto Colombiano Agropecuario como de mayor comercialización en el país (30).

Es importante resaltar que el mayor porcentaje de los plaguicidas empleados por la población de estudio pertenecen a la categoría toxicológica I, extremadamente tóxicos, seguido por la categoría III, medianamente tóxicos.

El plaguicida más frecuentemente utilizado fue el Gramoxone® (paraquat (1,1-dimetil,4,4bipiridilo), clasificado como extremadamente tóxico.

Es importante resaltar que los encuestados informaron el uso de plaguicidas organoclorados, los cuales se encuentran prohibidos en el país desde 1993 por el Ministerio de Salud (Resolución 10255/93).

Entre los plaguicidas de categoría toxicológica IV, el glifosato fue el más utilizado, lo que concuerda con informado en la literatura mundial (7), y se encontraron seis nombres comerciales cuyo ingrediente activo es $\mathrm{N}$-fosfonometil- glicina. Sin embargo, la población no reconoce que estos plaguicidas contienen glifosato.

Al ordenar los plaguicidas mencionados por los individuos del estudio teniendo en cuenta la $\mathrm{DL}_{50}$, se encontró que los plaguicidas con una menor $\mathrm{DL}_{50}$ fueron aquéllos que tienen como ingrediente activo el metamidofos, monocrotofos y paraquat, es decir, son los de mayor toxicidad. El glifosato fue el plaguicida con la mayor $\mathrm{DL}_{50}$, lo que indica menor toxicidad.

Un porcentaje muy bajo de las personas que utilizan plaguicidas recibieron capacitación sobre uso y manejo de los mismos alguna vez en su vida, razón por la cual la mayoría de los encuestados desconoce los posibles efectos que puede desencadenar la exposición a plaguicidas, y no tiene información sobre los elementos de protección y las medidas de higiene industrial que deben seguir cuando están trabajando con estas sustancias químicas. Aunque varias de las personas $(55,4 \%)$ refieren almacenar los plaguicidas fuera de la casa, $23,2 \%$ mencionó guardarlo dentro de la misma, lo cual puede ocasionar un incremento potencial de la exposición a plaguicidas, no sólo para el trabajador que lo utiliza sino para su familia, como está reportado en otros estudios (31).

Un aspecto crítico identificado es la forma como se almacenan y disponen estas sustancias y sus desechos. Los recipientes de los plaguicidas son reutilizados para almacenar agua y otros son quemados, enterrados, botados a campo abierto o arrojados al agua, lo que está ocasionando contaminación del medio ambiente.

En relación con los elementos de protección personal, se encontró que realizan las labores de aplicación de plaguicidas con la ropa de uso diario y no utilizan elementos de protección en cara, tronco ni manos; el uso de botas fue el único elemento que presentó una frecuencia importante; sin embargo, su uso se debe más a unaprotección detipofísico porlascondiciones del terreno en donde se labora que a una protección específica por el empleo de plaguicidas. Los individuos del estudio refirieron que no 
tienen uniforme o ropa especial para el trabajo con plaguicidas y, además, lavan esta ropa mezclada con el resto de ropa de la familia, exponiéndose los miembros de la familia al riesgo de intoxicación por dichas sustancias.

Esta situación explica cómo $12,5 \%$ de estas personas manifestaron haber sufrido en su vida alguna intoxicación con plaguicidas, específicamente con Furadan $\AA$, Tamaron $\AA$, Lannate $\AA$ y Metavin $\AA$, todos de categoría toxicológica I y pertenecientes al grupo de los organofosforados y carbamatos, los cuales son todavía los insecticidas más usados en el mundo y los que producen el mayor número de intoxicaciones agudas en nuestro país.

Cuando se presentó alguna sintomatología de intoxicación, sólo un pequeño porcentaje refirió consultar al médico y el resto prefirió tomar remedios caseros, lo que dificulta el correcto diagnóstico y tratamiento del paciente intoxicado, como también la notificación del caso al SIVIGILA. En consecuencia, se podría plantear la hipótesis de que existe un subregistro de los casos de intoxicación por plaguicidas reportados al SIVIGILA.

Por otro lado, al indagar sobre la actitud frente al Programa de Erradicación de Cultivos Ilícitos con Glifosato, sólo 7,1\% reconoce que es una política de Estado que debe llevarse a cabo, pero la mayoría de ellos piensan que las aspersiones producen efectos sobre la salud, el medio ambiente, los animales, afectan la economía y los cultivos lícitos. Como se ha expresado en otras publicaciones, se encuentran diferentes posiciones respecto a esta medida, las cuales son irreconciliables y ninguna puede considerarse irrefutable (32).

Entre las manifestaciones clínicas informadas, la mayoría de los síntomas se relacionan con alteraciones neurológicas y de piel. Las alteraciones neurológicas, como cefalea, mareo, sudoración profusa y visión borrosa, se pueden relacionar con el uso de plaguicidas organofosforados y carbamatos, mientras que las alteraciones en piel pueden desencadenarse con el empleo de cualquier sustancia química, incluidos los plaguicidas como glifosato, organo- fosforados y carbamatos (33). Igualmente, las manifestaciones del sistema digestivo, como vómito, náuseas, dolor abdominal y diarrea, se pueden presentar por la ingestión de múltiples sustancias químicas, pero también pueden tener origen bacteriano y viral, entre otras causas.

Del $39,6 \%$ de los individuos con glifosato cuantificable, $64,3 \%$ reportó el uso de este herbicida en sus actividades agrícolas $\mathrm{y}$, del $3,8 \%$ que presentaron el metabolito ácido aminometil-fosfónico, $50 \%$ igualmente lo empleaban en labores agrícolas. Es decir que el porcentaje restante de individuos que no lo empleaban directamente, pudieron haber tenido exposición por cercanía a los lugares donde se aplica el herbicida de forma manual o por las aspersiones aéreas con glifosato.

Se detectó que el departamento con el mayor número de individuos con glifosato y ácido amino-metil-fosfónico fue Putumayo, seguido por Guaviare, los cuales tienen amplia actividad agrícola y de cultivos ilícitos; por tanto, son zonas objeto del programa Programa de Erradicación de Cultivos Ilícitos con Glifosato.

Al relacionar los resultados cuantificados de glifosato y ácido amino-metil-fosfónico con los elementos de protección personal y las medidas de higiene industrial, aunque no se encontró ningunaasociaciónestadísticamentesignificativa, sí se describe el bajo uso de elementos de protección personal para ojos, vía respiratoria, tronco y miembros superiores e inferiores.

La sintomatología reportada en las encuestas relacionada con los niveles de glifosato y ácido amino-metil-fosfónico cuantificados, no dio tampoco asociaciones estadísticamente significativas. Los síntomas que con mayor frecuencia reportaron fueron cefalea, seguida por ardor ocular, fiebre, mareo y sequedad en la piel. Tanto la cefalea como el ardor ocular y la sequedad en la piel son manifestaciones que se pueden presentar por la exposición a glifosato; sin embargo, son muy inespecíficas y ocurren por exposición a múltiples sustancias químicas (34).

Al agrupar las manifestaciones clínicas por sistemas, los síntomas de piel, órganos de los 
sentidos y neurológicos se relacionaron con niveles de $2 \mu \mathrm{g} / \mathrm{L}$ o mayores. Los síntomas en piel, como eritema y prurito, se pueden presentar por exposición a glifosato, al igual que los de los órganos de los sentidos, como enrojecimiento de los ojos y ardor ocular, ya que este herbicida tiene acción irritante sobre piel y mucosas. Respecto al sistema nervioso, el glifosato no lo afecta; el síntoma más frecuente fue la cefalea, la cual puede desencaderse por innumerables causas.

Antecedentes toxicológicos como fumar o consumir licor, no se relacionaron con los niveles cuantificados de glifosato y de ácido aminometil-fosfónico. Específicamente, el hábito de fumar no incrementa la absorción por esta vía, debido a que este plaguicida no es una sustancia volátil que ingrese fácilmente por inhalación. En relación con la vía de exposición, los individuos que tenían glifosato cuantificado refirieron la respiratoria y la dérmica, las cuales están relacionadas con el ingreso del herbicida, tanto por las aspersiones aéreas como por su uso en actividades agrícolas.

La exposición a plaguicidas con glifosato como ingrediente activo en actividades agrícolas, no produjo un aumento significativo de los niveles cuantificables de glifosato y ácido amino-metilfosfónico en orina; es decir que el hecho de ser agricultor laboralmente expuesto a tales compuestos no se refleja en la detección de glifosato en orina o de su metabolito; esto se debe a la rápida excreción de este herbicida por el organismo (7-9).

Respecto al biomarcador de efecto, como es la determinación de la acetilcolinesterasa para evaluar la exposición a plaguicidas organofosforados y carbamatos (28), sólo el $8,7 \%$ de los que refirieron emplear estos plaguicidas presentaron valores anormales, a pesar de que fue el grupo químico más utilizado. Una limitación de nuestro estudio es que el valor de la actividad de la acetilcolinesterasa debe establecerse antes de la exposición a estas sustancias químicas $\mathrm{y}$, al menos, con un seguimiento en las 72 horas siguientes a la terminación de la exposición. Por lo tanto, el bajo porcentaje de individuos con valores anormales, puede deberse a que la muestra para la determinación de este biomarcador se tomó al mismo tiempo que se recolectaron las muestras para la determinación de glifosato y organoclorados, por lo que no se tuvo en cuenta el tiempo transcurrido entre la última exposición a organofosforados y carbamatos y la toma de la muestra. Ésta debe tomarse dentro de las primeras 72 horas después de terminada la exposición a este grupo de plaguicidas, debido a que la enzima comienza a regenerarse una vez cesa la exposición.

En los plaguicidas organoclorados, igualmente, se refleja la falta de uso de elementos de protección personaly la deficiencia de las medidas de higiene industrial. Aunque no se encontró una asociación estadísticamente significativa con las manifestaciones clínicas reportadas y su agrupación por sistemas, sí se evidenció que las manifestaciones del sistema nervioso $(47,3 \%)$ fueron las que con mayor frecuencia mencionaron los individuos con organoclorados en suero, seguidas por las de piel, $40,2 \%$. Esto se explica porque son plaguicidas altamente liposolubles, que se almacenan en órganos ricos en tejido graso, como el cerebro, y producen graves efectos neurotóxicos en el ser humano (28).

Aunque todos los plaguicidas organoclorados fueron prohibidos en el país a partir de 1993, por su alta persistencia, capacidad de biomagnificarse y por sus efectos neurotóxicos, los individuos del estudio reportaron el uso del tionil y el tiodan con endosulfán como ingrediente activo. Se encontraron en suero niveles de diez plaguicidas organoclorados; esto puede deberse a que son plaguicidas altamente persistentes y a que fueron ampliamente usados en nuestro país por 40 años, aproximadamente. Es importante resaltar que los individuos del estudio reportaron el uso actual de estos plaguicidas.

Los resultados de este trabajo ponen de manifiesto todos los riesgos asociados al uso de plaguicidas y la necesidad de fortalecer la vigilancia en salud pública sobre los potenciales efectos adversos sobre la salud que pueden producir estas sustancias químicas. 
Se hace necesario que se capacite tanto a los trabajadores como a sus familias sobre los posibles efectos que puede desencadenar la exposición a plaguicidas y sobre las prácticas de manejo seguro de estas sustancias $y$, de esta manera, dar cumplimiento a lo establecido en el Decreto 1843 de 1991 acerca de las disposiciones sanitarias sobre uso y manejo de plaguicidas. También, se les debe sensibilizar con el objeto de que hagan un empleo racional de estos productos y de que reduzcan de manera significativa el uso de plaguicidas de categoría toxicológica I y II.

Es indispensable que se capacite al trabajador en el uso de elementos de protección personal y de medidas de higiene industrial, con el fin de que empleen ropa ligera de trabajo que recubra la mayor parte de la superficie corporal cuando se vaya a mezclar o aplicar plaguicidas, así como cuando limpien el equipo y los recipientes vacíos o evacúen los restos del plaguicida utilizado. Además, deben emplear guantes, botas y mascarillas adecuadas para la manipulación de los plaguicidas.

Se hace necesario un esfuerzo conjunto de los organismos de salud, entidades educativas, secretarías de salud y organismos de protección ambiental, con el objeto de desarrollar programas de vigilancia epidemiológica para los trabajadores del sector informal y para sus familias. Las secretarías de salud deben reforzar la implementación del protocolo de Vigilancia en Salud Pública de las Intoxicaciones por Plaguicidas, establecido por el Ministerio de la Protección Social y el Instituto Nacional de Salud.

El hallazgo de plaguicidas organoclorados evidencia el tráfico ilegal de estos productos pese a que, en la mayoría de países, han sido prohibidos o severamente restringidos, y su presencia deja ver la debilidad de los organismos de control estatal. Ante esta situación y el desconocimiento de la comunidad sobre los graves riesgos para la salud humana, animal y del ambiente, es necesario emprender campañas de divulgación masiva para advertir a la población sobre las implicaciones de su empleo.
Parte de las medidas de intervención de la problemática es el fomento del suministro de elementos de proteccion personal, particularmente en los trabajadores independientes 0 informales que no tienen recursos para adquirir dichos elementos.

No se encontró asociación con la detección de biomarcadores y el uso de alguna medida de protección personal, debido a que los trabajadores agrícolas expuestos a plaguicidas que participaron en el estudio no utilizan el conjunto de medidas de protección personal nesesarias para la manipulación de los plaguicidas; su analisis se hizo de manera individual, con variaciones que van desde su ausencia hasta una utilización de 50\% o menos de ellos. Es de anotar que muchos de los elementos referidos no son utilizados como medidas de protección en sí, sino que son de uso rutinario u obedecen a otras condiciones, como el empleo de las botas.

La metodología de este estudio permitió sólo la valoración de los efectos agudos. Después de hacer el análisis de la información, no se encontraron hallazgos concluyentes sobre la exposición al glifosato empleado en la erradicación de cultivos ilícitos y los efectos en la salud, debido a que se halló exposición ocupacional (uso agrícola) concomitante por la misma sustancia y por otras de mayor toxicidad que el herbicida empleado en el Programa de Erradicación de Cultivos llícitos con Glifosato.

\section{Agradecimientos}

A los directivos de las entidades territoriales de salud que respaldaron al equipo investigador del Instituto Nacional de Salud y, particularmente, a los funcionarios que realizaron el acompañamiento durante el desarrollo del trabajo de campo. Nuestro reconocimiento al Departamento Administrativo de Salud del Putumayo y a la epidemióloga Dyva Revelo Calderón; a la Secretaría de Salud de Santa Marta, por la colaboración de la epidemióloga Nazly Goenaga; a la Secretaría Departamental de Salud del Guaviare (E) y a la Directora de Salud Pública, Oveida Parra y Alba Colorado; a la 
Dirección Seccional de Salud de Antioquia, a la epidemióloga Zulma del Campo Tabarez y a los técnicos de Salud Ambiental, Rosendo Orozco y Elidio Seguro.

Finalmente, agradecemos muy especialmente a la comunidad en general por haber contribuido con la realización de este estudio, al aceptar responder la encuesta y haber accedido a que se les tomaran las muestras para el mismo.

\section{Conflicto de intereses}

Los autores declaran que no existe ningún conflicto de intereses en esta publicación.

\section{Financiación}

Esta investigación fue financiada por el Ministerio de la Protección Social y el Instituto Nacional de Salud.

\section{Referencias}

1. Internacional Programme on Chemical Safety (IPCS). The WHO recommended classification of pesticides by hazard and guidelines to classifictation. Geneva: World Health Organization; 2004.

2. Salazar C, González G, Arcila O. Guaviare. Población y territorio. Instituto Amazónico de Investigaciones Científicas, SINCHI, Ministerio del Medio Ambiente. Bogotá D.C.: TM Editores; 1999. p. 1-193.

3. Grupo Factores de Riesgo Ambiental, Subdirección de Vigilancia y Control. Intoxicaciones por sustancias químicas en Colombia notificadas al SIVIGILA. Bogotá D.C.: Instituto Nacional de Salud; 2007.

4. Bernal HH, Paredes M. Impacto ambiental ocasionado por las sustancias químicas, los cultivos ilícitos y actividades conexas. Santa Fe de Bogotá: Dirección Nacional de Estupefacientes; 2001. p. 42. Fecha de consulta: 21 de octubre de 2003. Disponible en: http:// www.dne.gov.co/?idcategoria $=790$

5. Ministerio de Salud. Decreto 1843 del 22 de julio de 1991. Disposiciones sanitarias sobre uso y manejo de plaguicidas. Bogotá: Ministerio de Salud; 1991. p. 1-69.

6. Dirección Nacional de Estupefacientes. La lucha de Colombia contra las drogas ilícitas: acciones y Resultados. Bogotá D.C.: DNE; 2002.

7. Solomon K, Anedón A, Cerdeira A, Marshall J, Sanín L. Estudio de los efectos del programa de erradicación de cultivos ilícitos mediante la aspersión aérea con el herbicida glifosato (PECIG) y de los cultivos ilícitos en la salud humana y en el medio ambiente. Bogotá, D.C.: CICAD; 2005. Fecha de consulta: 22 de febrero de 2008. Disponible en: http://www.dne.gov.co/index. php?idcategoria $=792$
8. Burger M, Fernández S. Exposición al herbicida glifosato: aspectos clínicos toxicológicos. Rev Med Uruguay. 2004;20:202-7.

9. Williams GM, Kroes R, Munro IC. Safety evaluation and risk assessment of the herbicide Roundup and its active ingredient, glyphosate for humans. Regul Toxicol Pharmacol. 2000;31:117-65.

10. Devine MD, Duke So, Fedtke C. Physiology of herbicide action. Englewood Cliffs, NJ: PTR Prentice Hall; 1993.

11. Ministerio de Salud, Instituto Nacional de Salud. Información sobre glifosato. Uso y toxicología. Santa Fé de Bogotá: Ministerio de Salud, INS; 1992.

12. United States Environmental Protection Agency (EPA). Registration eligibility decision facts. Glyphosate. Publication No. EPA-738-F-93-011. Washington D.C.: EPA; 1993.

13. Worthing CR, Hance RJ. The pesticide manual. 9th edition. Surrey, Great Britain: The British Crop Protection Council; 1991. p. 459-60.

14. Chang CY, Peng YC, Hung DZ, Hu WH, Yang DY, Lin TJ. Clinical impact of upper gastrointestinal tract injuries in glyphosate-surfactant oral intoxication. Hum Exp Toxicol. 1999;18:475-8.

15. Lee HL, Chen KW, Chi CH, Huang JJ, Tsai LM. Clinical presentations and prognostic factors of a glyphosate surfactant herbicide intoxication: a review of 131 cases. Acad Emerg Med. 2000;7:906-10.

16. Monroy CM, Cortés AC, Sicard DM, Groot H. Citotoxicidad y genotoxicidad en células humanas expuestas in vitro a glifosato. Biomédica. 2005;25:335-45.

17. Ministerio de Defensa. Identificación del herbicida glifosato, propiedades y toxicidad. 2002. Fecha de consulta: 22 de febrero de 2008. Disponible en: http:// www.dne.gov.co/recursos_user/documentos/Doc tecnicos/glifosato.pdf.

18. Unidad Administrativa Especial, Dirección Nacional de Estupefacientes, Ministerio de Justicia y del Derecho. Identificación del herbicida a aplicar, propiedades y toxicidad. Plan de manejo ambiental para la aplicación del herbicida glifosato en la erradicación de cultivos ilícitos. Documento técnico. Santa Fe de Bogotá: Ministerio de Justicia y del Derecho; 1998.

19. Environmental Protection Agency (EPA). Consumer factsheet on: Glyphosate. Ground water and drinking water, 1995. Fecha de consulta: 22 de febrero de 2008. Disponible en: http://www.epa.gov/ogwdw000/ contaminants/dw_contamfs/glyphosa.html

20. Jauhiainen A, Räsänen K, Sarantila R, Nuutinen J, Kangas J. Occupational exposure of forest workers to glyphosate during brush saw spraying work. Am Ind Hyg Assoc J. 1991;52:61-4.

21. Cox C. Herbicide factsheet: Glyphosate (Roundup). Journal of Pesticide Reform. 1998;18:3-17. 
22. University of Idaho, University of California at Davis, Institute for Environmental Toxicology, Michigan State University, National Agricultural. Extension toxicology network. Pesticide information profiles. Glyphosate. 1996. Fecha de consulta: 22 de febrero de 2008. Disponible en: http://extoxnet.orst.edu/pips/ glyphosa.htm

23. De Ross A, Blair A, Rusiecki J, Hoppin J, Svec M, Dosemeci M, et al. Cancer incidence among glyphosateexposed pesticide applicators in the agricultural health study. Environ Health Perspect. 2005;113:49-54.

24. Revelo D. Efectos de la fumigación aérea con glifosato. Valle del Guamuez-San Miguel-Orito. Mocoa: Dasalud Putumayo, Oficina de Planeación, Sección Epidemiología; 2001. p. 24.

25. Uribe C. Supuestos efectos del glifosato en la salud humana. Clínica de Toxicología Uribe Cualla. Informe técnico. 2001. Fecha de consulta: 22 de febrero de 2008. Disponible en: http://www.ciponline.org/colombia/ wwwfuc1s.pdf

26. Limperos G, Ranta KE. A rapid screening test for the determination of the approximate cholinesterase activity of human blood. Science. 1953;117:453-5.

27. United States Environmental Protection Agency (EPA). Manual of analytical methods for pesticides in humans and environmental samples. A compilation of methods selected for use in pesticide monitoring programs. Analysis of human blood or serum. Publication No. EPA-600/8-80-038. Section 5, A(3),(a). Atlanta, USA: U.S Government Printing Office; 1980. p. 1-7
28. Córdoba D. Toxicología. Cuarta Edición. Bogotá Editorial Manual Moderno; 2000. p. 121-6.

29. Organización Panamericana de la Salud. Vigilancia sanitaria de plaguicidas: experiencia de Plagsalud en Centroamérica. Washington D.C: OPS; 2004.

30. Grupo Regulación y Control de Plaguicidas Químicos de Uso Agrícola, Instituto Colombiano Agropecuario. Comercialización de plaguicidas. Producción-ventasimportación-exportación. Bogotá: Editorial Produmedios; 2002.

31. Acquavella J, Alexander B, Mandel J, Gustin C, Baker B, Chapman P, et al. Glyphosate biomonitoring for farmers and their families: results from the Farm Family Exposure Study. Environ Health Perspect. 2004;112:321-6.

32. Idrovo A. Plaguicidas usados en la fumigación de cultivos ilícitos y salud humana: ¿una cuestión de ciencia o política? Rev Salud Pública. 2004;6:199-211.

33. Nagami H, Nishigaki Y, Matsushima S, Matsushita T, Asanuma S, Yajima N, et al. Hospital-based survey of pesticide poisoning in Japan, 1998-2002. Int J Occup Environ Health. 2005;11:180-4.

34. Williams G, Kroes R, Munro I. Safety evaluation and risk assessment of the herbicide Roundup and its active ingredient, glyphosate, for humans. Regul Toxicol Pharmacol. 2000;31:117-65. 